Supporting Information for:

\title{
Optical Excitations in a Carbon Architecture Based on Dodecadehydrotribenzo [18] annulene
}

\author{
Sridhar Arun Lahankar, ${ }^{\dagger}$ Smriti Anand ${ }^{\dagger}$ Jeremiah A. Marsden, ${ }^{\ddagger}$
} Michael M. Haley, ${ }^{\star}$ H. Bernhard Schlegel, ${ }^{\dagger}$ Theodore Goodson III $^{\dagger, *}$

Contribution from the Department of Chemistry and Institute of Scientific Computing, Wayne State University, Detroit, Michigan 48202, and the Department of Chemistry and Material Science Institute, University of Oregon, Eugene, Oregon 97403-1253 

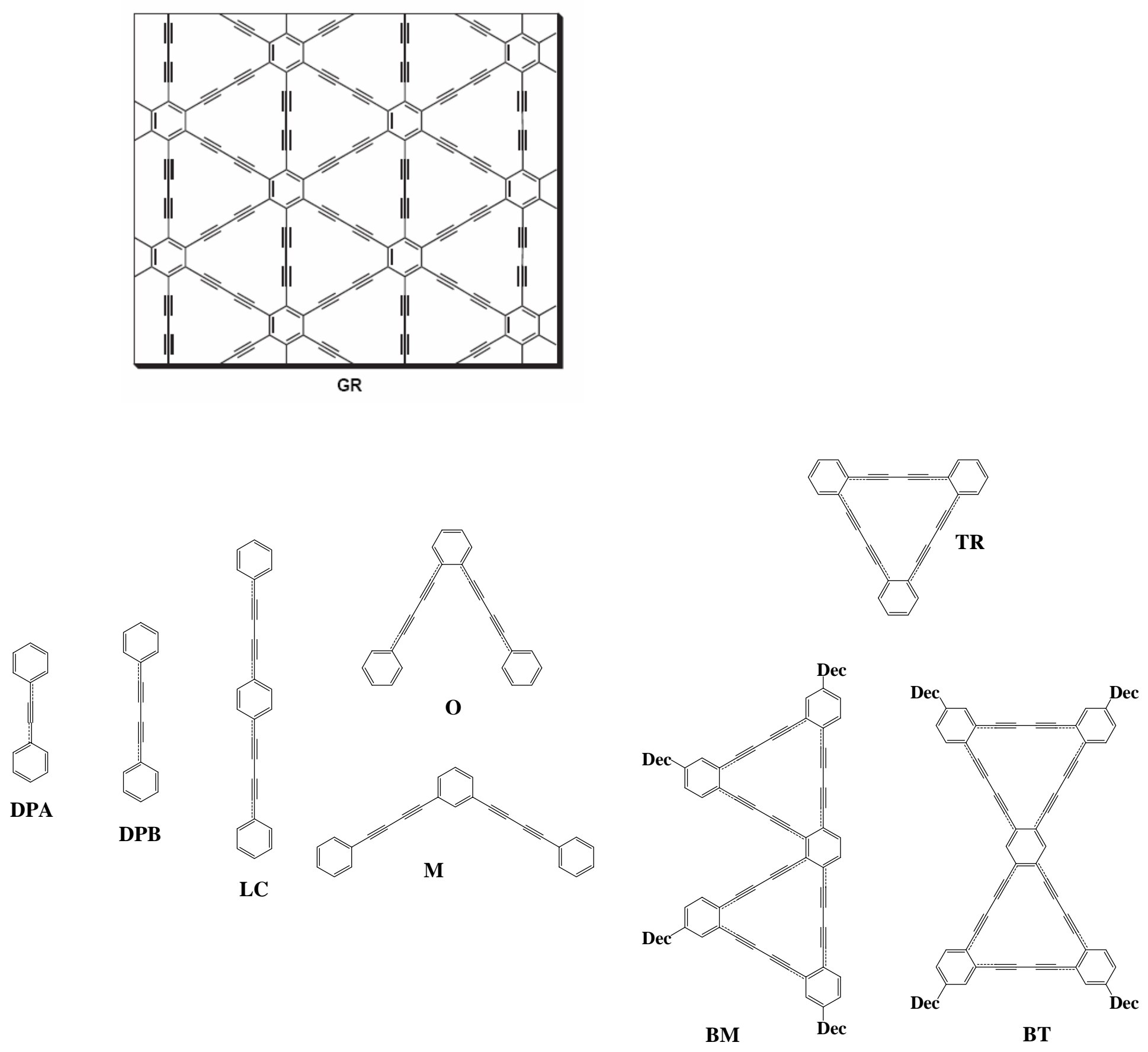

Scheme 1 
1,4-Bis(4-phenylbuta-1,3-diynyl)benzene. Tetrabutylammonium fluoride (1M THF) (17.2 mL, $17.12 \mathrm{mmol}$ ) was added to a solution of 4-(triisopropylsilyl)-1,3butadiynylbenzene $(0.97 \mathrm{~g}, 3.43 \mathrm{mmol})$ dissolved in THF $(50 \mathrm{~mL})$ and EtOH $(5 \mathrm{~mL})$. The reaction was stirred under $\mathrm{N}_{2}$ at $\mathrm{rt}$ for $2 \mathrm{~h}$, after which the solution was diluted with $\mathrm{Et}_{2} \mathrm{O}(50 \mathrm{~mL})$ and washed twice with $\mathrm{H}_{2} \mathrm{O}(50 \mathrm{~mL})$ then brine $(50 \mathrm{~mL})$, dried over $\mathrm{MgSO}_{4}$ and the solvent evaporated to give crude 1,3-butadiynylbenzene. The material was redissolved in THF $(50 \mathrm{~mL})$ and diisopropylamine $(100 \mathrm{~mL})$. The solution was purged with $\mathrm{N}_{2}$ for $1 \mathrm{~h}$, then 1,4-diiodobenzene (0.48 g, $\left.1.44 \mathrm{mmol}\right), \mathrm{Pd}\left(\mathrm{PPh}_{3}\right)_{4}(0.11 \mathrm{~g}, 0.10$ mmol), and $\mathrm{CuI}(0.05 \mathrm{~g}, 0.28 \mathrm{mmol})$ were added. The vessel was sealed under $\mathrm{N}_{2}$ and stirred for $12 \mathrm{~h}$ at $\mathrm{rt}$. The solution was then diluted with $\mathrm{CH}_{2} \mathrm{Cl}_{2}(1000 \mathrm{~mL})$ and washed three times with $5 \% \mathrm{HCl}(300 \mathrm{~mL})$. The solution was dried over $\mathrm{MgSO}_{4}$ and filtered through a small cake of silica. The solvent was evaporated and the crude material was triturated twice (2:1 hexanes: $\left.\mathrm{CH}_{2} \mathrm{Cl}_{2}, 20 \mathrm{~mL}\right)$ and filtered to give 1,4bis(phenylbutadiynyl)benzene $(0.41 \mathrm{~g}, 87 \%)$ as a tan solid. Mp: $260-262{ }^{\circ} \mathrm{C}$. (Literature Mp: $\left.258-260^{\circ} \mathrm{C}\right)^{1}$ All spectral data agreed with the literature values.

1) White, D. M.; Quinn, C. B. J. Polym. Sci., Polym. Chem. Ed. 1977, 15, 2595-2602. 